Res., Soc. Dev. 2019; 8(4):e2784867

ISSN 2525-3409 | DOI: http://dx.doi.org/10.33448/rsd-v8i4.867

\title{
Análise do Acesso da População Brasileira a Serviços de Saneamento Básico
}

Analysis of the Access of the Brazilian Population to Basic Sanitation Services

Análisis del Acceso de la Población Brasileña a Servicios de Saneamiento Básico

Fernanda Beatryz Rolim Tavares

ORCID: https://orcid.org/0000-0002-5724-8184

Universidade Federal de Campina Grande, Brasil

E-mail: nanda_sodi@hotmail.com

Fernando Chagas de Figueiredo Sousa

ORCID: https://orcid.org/0000-0003-1795-3310

Instituto Federal da Paraiba, Brasil

E-mail: sousaf.figueiredo@gmail.com

Vanessa Érica da Silva Santos

ORCID: https://orcid.org/0000-0002-1355-4198

Universidade Federal de Campina Grande, Brasil

E-mail: vanessa.erica@hotmail.com

Érika Lira da Silva

ORCID: https://orcid.org/0000-0003-2812-6265

Universidade Federal de Campina Grande, Brasil

E-mail: erikaliradasilva@gmail.com

Recebido: 22/12/2018 | Revisado: 26/01/2019 | Aceito: 30/01/2019 | Publicado: 26/02/2019

\section{Resumo}

O saneamento básico corresponde ao conjunto de serviços de abastecimento público de água potável, coleta, tratamento e disposição final adequada dos esgotos sanitários, drenagem e manejo das águas pluviais urbanas, além da limpeza urbana e o manejo dos resíduos sólidos é regido pela Lei Federal 11.445/07 (Lei Federal do Saneamento Básico). A Organização Mundial da Saúde (OMS) define saneamento como um controle de fatores do meio físico que podem causar efeitos nocivos sobre o ser humano, seja sobre seu bem-estar físico, mental ou social. O estudo objetiva apresentar um contexto acerca da temática envolvendo a legislação vigente no Brasil, bem como teorias abordadas por pesquisadores a fim de discutir e compreender melhor a temática. Sendo assim, buscou-se demonstrar e apresentar a realidade brasileira através do método dedutivo e da técnica de pesquisa documental e 
bibliográfica, a partir de dados levantados pelo Instituto Brasileiro de Geografia e Estatística (IBGE), em sua Pesquisa Nacional por Amostra de Domicílios (PNAD), realizada no período de 2005 a 2015, no qual se evidenciou uma necessidade de Gestão voltada ao problema, dado a apresentação de números alarmantes.

Palavras-chave: Saneamento Básico; Política Nacional; IBGE.

\begin{abstract}
Basic sanitation corresponds to the set of public drinking water supply services, collection, treatment and adequate final disposal of sanitary sewage, drainage and management of urban rainwater, besides urban cleaning and solid waste management is governed by Federal Law 11.445 / 07 (Federal Basic Sanitation Law). The World Health Organization (WHO) defines sanitation as a control of physical factors that can cause harmful effects on the human being, be it physical, mental or social well-being. The objective of this study is to present a context about the topic of legislation in Brazil, as well as theories addressed by researchers in order to better discuss and understand the theme. Thus, we sought to demonstrate and present the Brazilian reality through the deductive method and the documentary and bibliographic research technique, based on data collected by the Brazilian Institute of Geography and Statistics (IBGE), in its National Household Sample Survey ( PNAD), carried out in the period from 2005 to 2015, in which there was a need for Management focused on the problem, given the presentation of alarming numbers.
\end{abstract}

Keywords: Basic sanitation; National Policy; IBGE.

\title{
Resumen
}

El saneamiento básico corresponde al conjunto de servicios de abastecimiento público de agua potable, recolección, tratamiento y disposición final adecuada de las alcantarillas sanitarias, drenaje y manejo de las aguas pluviales urbanas, además de la limpieza urbana y el manejo de los residuos sólidos está regido por la Ley Federal 11.445 / 07 (Ley Federal del Saneamiento Básico). La Organización Mundial de la Salud (OMS) define el saneamiento como un control de factores del medio físico que pueden causar efectos nocivos sobre el ser humano, ya sea sobre su bienestar físico, mental o social. El estudio objetiva presentar un contexto acerca de la temática involucrando la legislación vigente en Brasil, así como teorías abordadas por investigadores a fin de discutir y comprender mejor la temática. Por lo tanto, se buscó demostrar y presentar la realidad brasileña a través del método deductivo y de la técnica de investigación documental y bibliográfica, a partir de datos levantados por el Instituto Brasileño de Geografía y Estadística (IBGE), en su Encuesta Nacional por Muestra de Domicilios (IBGE) (PNAD), realizada en el período de 2005 a 2015, en el cual se evidenció una necesidad de Gestión volcada al problema, dado la presentación de números alarmantes.

Palabras clave: Saneamiento; Política Nacional; IBGE. 


\section{Introdução}

O saneamento básico refere-se a atividades relacionadas com o abastecimento de água potável, manejo de águas pluviais, coleta e tratamento de esgoto, limpeza urbana, manejo de resíduos sólidos e controle de pragas ou outros agentes patogênicos, a qual objetiva alcançar e manter a saúde, proporcionando uma situação saudável para a população. Esses serviços são tratados como essenciais, pois possuem um grande impacto e importância para a saúde e meio ambiente, podendo ser prestados por empresas públicas ou privadas (regime de concessão).

No Brasil, a Lei $\mathrm{n}^{\circ}$ 11.445/2007 garante o saneamento básico como um direito e assegura esse conjunto de serviços, infraestrutura e Instalações operacionais de abastecimento de água, esgotamento sanitário, limpeza urbana, drenagem urbana, manejos de resíduos sólidos e de águas pluviais. Também define que o munícipio é o responsável pelo planejamento do saneamento básico, e a prestação dos serviços pode ser feita pelo ente público municipal ou por concessionária pública e/ou privada. Os três níveis de governo (Municipal, Estadual e Federal) são responsáveis por adotar medidas que visem a melhoria da vida e da saúde da população, buscando reduzir fatores físicos de efeitos nocivos prejudiciais as pessoas no seu bem-estar físico mental e social.

No entanto, verifica-se que ainda há lacunas legislativas que não trazem forças coercitivas suficientes para trazer uma eficácia gerencial adequada, de modo a evidenciar um descumprimento pelas esferas governamentais.

A qualidade de vida humana está relacionada ao saneamento básico, uma vez que ele auxilia na melhoria da saúde através de um conjunto de medidas, garante a preservação do meio ambiente, o abastecimento e tratamento da água e a manutenção dos sistemas de esgotos.

Assim, pode ser considerado como um caminho para efetivar a saúde da população, onde se trabalha a ideia de saúde pública preventiva, em busca de reduzir doenças, chances de contágios, consequentemente a não necessidade da busca por hospitais e outros meios para remediar um mal já causado. Por meio do saneamento se objetiva efetivar um controle prévio, a fim de gerar maiores probabilidades de uma vida mais saudável da população e redução de índices de mortalidade, garantindo uma vida digna ao cidadão.

Na referida análise busca-se diagnosticar as referidas aplicações legislativas, tendo em vista que se tratam de direitos assegurados constitucionalmente e que garantiriam um bem estar social almejado. 
Partindo do exposto na legislação brasileira e apresentação da importância do saneamento básico a toda população, o presente estudo visa, além de conceituar, abordar e demonstrar a realidade brasileira nesse contexto, através de dados levantados pelo Instituto Brasileiro de Geografia e Estatística (IBGE), em sua Pesquisa Nacional por Amostra de Domicílios (PNAD), realizada no período de 2005 a 2015.

\section{Metodologia}

O presente estudo foi desenvolvido por meio de pesquisa bibliográfica, para auxiliar na compreensão do contexto, com base conceitual, acerca dos serviços de saneamento básico, considerado um direito fundamental a sociedade, para assim demonstrar e discutir como se encontra a realidade desse acesso à população brasileira.

A pesquisa do tipo bibliográfica possibilita alcançar diversas informações que agregam conhecimento ao conteúdo, permitindo acesso a inúmeras publicações a fim de formular uma melhor definição conceitual que envolve o objeto de estudo proposto. Para Gil (2008) essa pesquisa desenvolve-se através de materiais já elaborados por outros autores, tais como: Livros, publicações periódicas e obras acadêmicas.

Em relação a abordagem, considera-se o tipo qualitativa e quantitativa, tendo em vista que estes são métodos que podem se complementar, auxiliando para grande melhoria nos resultados obtidos. A pesquisa qualitativa contribui com o aprofundamento da compreensão do conteúdo exposto, com uma análise profunda diante o contexto e com as pesquisas apresentadas como fontes para a análise dos resultados. Já a pesquisa quantitativa irá auxiliar nessa interpretação, no momento que forem colhidos os dados para comprovação do estudo proposto, auxiliando assim responder o questionamento que move a pesquisa.

Dias (2014) descreve a pesquisa qualitativa principalmente pela ausência de medidas numéricas e análises estatísticas, analisando de maneira mais profunda e subjetiva, já na pesquisa quantitativa existe a possibilidade de medidas quantificáveis de variáveis e inferências a partir de amostras. Esse tipo de pesquisa utiliza medidas numéricas para testar hipóteses, ou busca padrões numéricos relacionados a conceitos cotidianos.

Dessa forma, é possível utiliza-se de várias informações acerca do assunto, bem como opiniões de diversos autores, promovendo uma melhor compreensão e debate sobre o conteúdo, auxiliando a relacionando as abordagens tratadas entre educação, meio ambiente e a gestão ambiental.

Os dados para o estudo foram coletados pelo Instituto Brasileiro de Geografia e 
Estatística (IBGE) e as informações são apresentadas em gráficos, retratando o estudo das condições em que se encontram os domicílios brasileiros mediante o acesso a serviços de saneamento nos anos de 2005 a 2015.

\section{Saneamento Básico como Direito Fundamental}

O saneamento básico é um conjunto de serviços de abastecimento público de água potável, coleta, tratamento e disposição final adequada dos esgotos sanitários, drenagem e manejo das águas pluviais urbanas, além da limpeza urbana e o manejo dos resíduos sólidos, e está assegurado pela Lei Federal 11.445/07 (Lei Federal do Saneamento Básico). A limpeza urbana e o manejo de resíduos sólidos são considerados como prestação de serviços públicos e engloba as atividades de coleta, transbordo e transporte dos resíduos; triagem para fins de reuso ou reciclagem; tratamento, incluindo compostagem, e disposição final dos resíduos.

Os Governos em suas três esferas, são responsáveis por adotar medidas que visem a melhoria da vida e da saúde da população, buscando reduzir fatores físicos de efeitos nocivos prejudiciais as pessoas no seu bem-estar físico mental e social, de modo a atender os direitos sociais previstos da $\mathrm{CF} / 88$.

De acordo com a Lei Federal n ${ }^{\circ} 11.445$, devem estar em conjunto o abastecimento de água tratada, coleta e tratamento de esgoto; limpeza urbana; manejo de resíduos sólidos e drenagem das águas pluviais. Esta Lei também estabelece diretrizes nacionais e a política federal ao saneamento, bem como define o munícipio como responsável pelo planejamento do saneamento básico. Aborda ainda que a prestação dos serviços pode ser feita pelo ente público municipal ou por concessionária pública e/ou privada.

A partir da referida previsão, pode-se evidenciar que o legislador já se preocupou em efetivar o saneamento básico, fazendo distribuições de competências para que assim os entes federativos sejam norteados.

Sarlet (2011) aborda o saneamento básico como uma política Nacional que trata de serviços de água e saneamento prestado pelo Estado ou empresa concessionária de serviço publico a uma determinada população, no que se refere a abastecimento de água potável, ao esgotamento sanitário, a limpeza urbana e manejo de resíduos sólidos e a drenagem e manejo das águas pluviais urbanas.

O acesso aos serviços adequados de água e esgoto é um importante determinante das condições de vida da população e da salubridade do meio ambiente (IPEA, 2010). É necessário atuar em adequação para o combate da pobreza e degradação do meio ambiente, 


\section{Res., Soc. Dev. 2019; 8(4):e2784867}

ISSN 2525-3409 | DOI: http://dx.doi.org/10.33448/rsd-v8i4.867

sendo que este serviço é integrante dos direitos fundamentais sociais, como o direito à saúde, o direito ao ambiente, incluindo o direito à água, essencial a dignidade humana (Sarlet, 2011).

A Organização Mundial da Saúde (OMS) define saneamento como um controle de fatores do meio físico que podem causar efeitos nocivos sobre o ser humano, seja sobre seu bem-estar físico, mental ou social.

Para Trindade (1993), o direito a um meio ambiente sadio acarreta e amplia o direito a saúde e a um padrão de vida adequado ao cidadão, onde salvaguarda a própria vida humana, seja pela existência física e saúde dos seres humanos, a dignidade desta existência, e a qualidade de vida.

No Brasil há um grande déficit em relação ao saneamento básico, gerando aspectos negativos a qualidade de uma vida digna à parcela da população. $O$ Índice de Desenvolvimento Humano (IDH) estima que aproximadamente 40 milhões de pessoas vivem abaixo da linha de pobreza no Brasil e que sem renda para se alimentar e sem teto, esse individuo acaba por se marginalizar, excluir e impede seu desenvolvimento físico e psíquico (Demoliner, 2008).

Assim, assegurar o acesso de saneamento à população mais abastada, leva a diminuição de mazelas multifatoriais, contribuindo para a efetivação dos preceitos constitucionais sensíveis.

\section{Saneamento Básico no Brasil}

O Brasil passa por alguns desafios, levando em consideração a expansão urbana, o aumento da poluição dos recursos hídricos, à precariedade de recursos financeiros, mudanças das políticas governamentais e dificuldades de uma ordenação institucional em relação à cobertura e a qualidade dos serviços de saneamento ambiental em todo o País (Hespanhol, 2006).

O Programa Saneamento para todos, que objetiva promover uma melhoria das condições de saúde e a qualidade de vida da população por meio de ações integradas e articuladas de saneamento básico urbano com outras políticas setoriais. Esse programa financia empreendimentos de saneamento dos setores público e privado, com o intuito de promover o aumento da cobertura e a qualidade dos serviços de abastecimento de saneamento. Outro programa é o de Serviços Urbanos de Água e Esgoto que tem como objetivo ampliar o acesso e melhorar a qualidade dos serviços de abastecimento de água e esgotamento sanitário nos municípios, com finalidade de suprir as deficiências de cobertura e 


\section{Res., Soc. Dev. 2019; 8(4):e2784867}

ISSN 2525-3409 | DOI: http://dx.doi.org/10.33448/rsd-v8i4.867

de qualidade dos serviços de saneamento ambiental, que atingem de forma mais intensa a população de menor nível socioeconômico, com consequências negativas sobre o ambiente e a qualidade de vida nas cidades (IPEA, 2010).

Mejia et al. (2003) aborda uma desigualdade de acesso a rede de esgoto, afirma que, a proporção de domicílios com acesso aos serviços difere bastante de uma região para outra e os mais pobres têm menor probabilidade de obter acesso a um nível adequado de serviços do que o restante da população. De acordo com Saiani (2007), o déficit de acesso aos serviços de saneamento básico no Brasil está intimamente relacionado ao perfil de renda dos consumidores, capacidade de pagamento (tarifas) e, à existência de economias de escala e de densidade no setor, maior facilidade de ofertar os serviços em grandes concentrações populacionais (aglomerações), uma vez que a expansão e a manutenção destes tendem a ter custos reduzidos à medida que aumenta o tamanho da população a ser atingida. Dessa forma pode ser visto que, o pensamento no retorno social que esses serviços podem gerar ainda é baixo, onde não há uma real preocupação no âmbito nacional que acarrete um investimento nesse sentindo.

O problema da ausência de saneamento básico da população, além de causar um dano social gera um estrago no âmbito de poluição do meio ambiente e, Moreira (2005) relata sobre isso, quando diz que no esgotamento sanitário, embora a população incorporada seja significativa, os indicadores de coleta de esgotos ainda são insatisfatórios (pelo menos 39 milhões de pessoas ainda não têm acesso a este serviço) e os de destinação e tratamento de esgotos são sofríveis.

Há um déficit que se distribui de forma desigual pelo país e é possível observar, por exemplo: um sério desequilíbrio entre o número de domicílios servidos por rede de água e o número de domicílios que possuem rede coletora de esgoto uma concentração do melhor atendimento nos grandes centros, em detrimento da periferia e do interior (Barat, 2004).

A população que possui renda baixa é, geralmente, a que mais se prejudica, uma vez que as ações governamentais visão lucro e não o bem social. Dos avanços obtidos, principalmente no que se refere aos serviços de abastecimento de água, o modelo estava orientado fundamentalmente para realizar inversões nas áreas urbanas e nos serviços mais rentáveis, deixando de lado os serviços de esgotamento sanitário e os segmentos sociais que não podiam assumir os custos da política tarifária (Oliveira, 2006).

As cidades brasileiras não têm conseguido oferecer infraestrutura urbana necessária para acompanhar o mesmo ritmo do crescimento populacional, sendo assim o atendimento mínimo necessário não consegue ser distribuído a toda população (Pires, 2009). 


\section{Resultados e Discussão}

Inicialmente importante abordar que a Pesquisa Nacional por Amostra de Domicílios (PNAD) identificou 68 milhões de domicílios particulares permanentes e 140 mil domicílios particulares improvisados, onde comparando com 2005 verifica-se um adicional de 14,8 milhões em relação ao total. Esse crescimento deu-se num ritmo bastante diverso entre as regiões, como pode-se conferir na Figura 1, que apresenta a comparação do total (em milhões) de domicílios particulares em cada uma das Grandes Regiões, em 2005 e 2015.

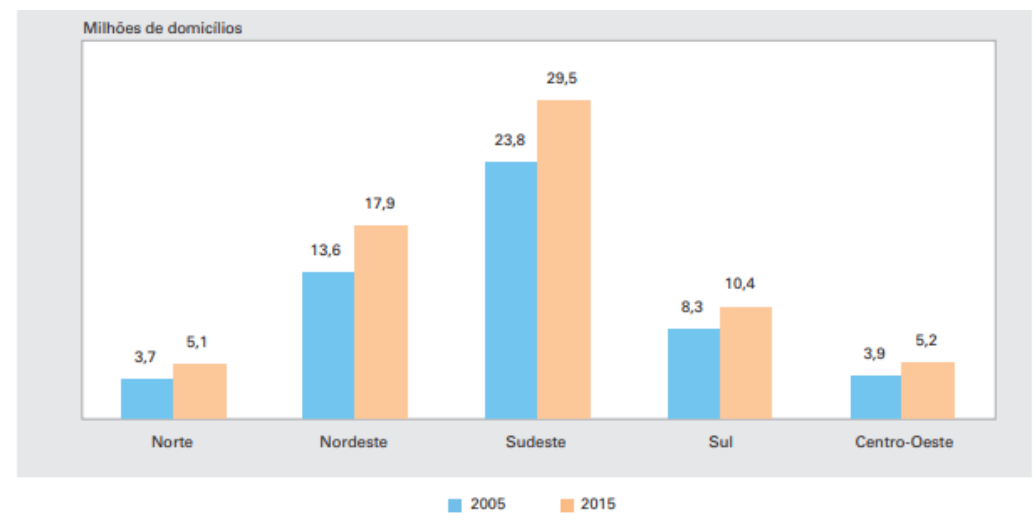

FIGURA 1: Número de domicílios particulares, segundo as Grandes Regiões - 2005/2015 FONTE: IBGE, Pesquisa Nacional por Amostra de Domicílios 2005/2015.

Essa expansão é percebida com maiores valores na Região Sudeste, com adição de 5,7 milhões de domicílios particulares. Porém, trazendo também um destaque a Região Norte, com um crescimento bem acelerado, onde em apenas uma década saltou $36,5 \%$ de seus domicílios. O IBGE ainda compara esse ritmo de crescimento de domicílios que foi bem maior do que o crescimento da população, ou seja, representando uma redução da média de moradores por domicílio. Seus dados divulgam que a média de moradores por domicílio particular era de 3,5, em 2005, reduzindo-se para 3,0 em 2015. A Figura 2 demonstra bem esse indicador, representando o número médio de moradores dos domicílios particulares, pode-se perceber uma significativa variação regional, mais elevado nas Regiões Norte e Nordeste, e mais baixo nas Regiões Sul e Sudeste. Esse indicador também registra significativa variação regional, sendo mais elevado nas Regiões Norte e Nordeste, e mais baixo nas Regiões Sul e Sudeste. Entre as Unidades da Federação, os pontos extremos são os Estados do Amazonas, com uma média de 3,8 moradores por domicílio particular, e do Rio Grande do Sul, com 2,7. 


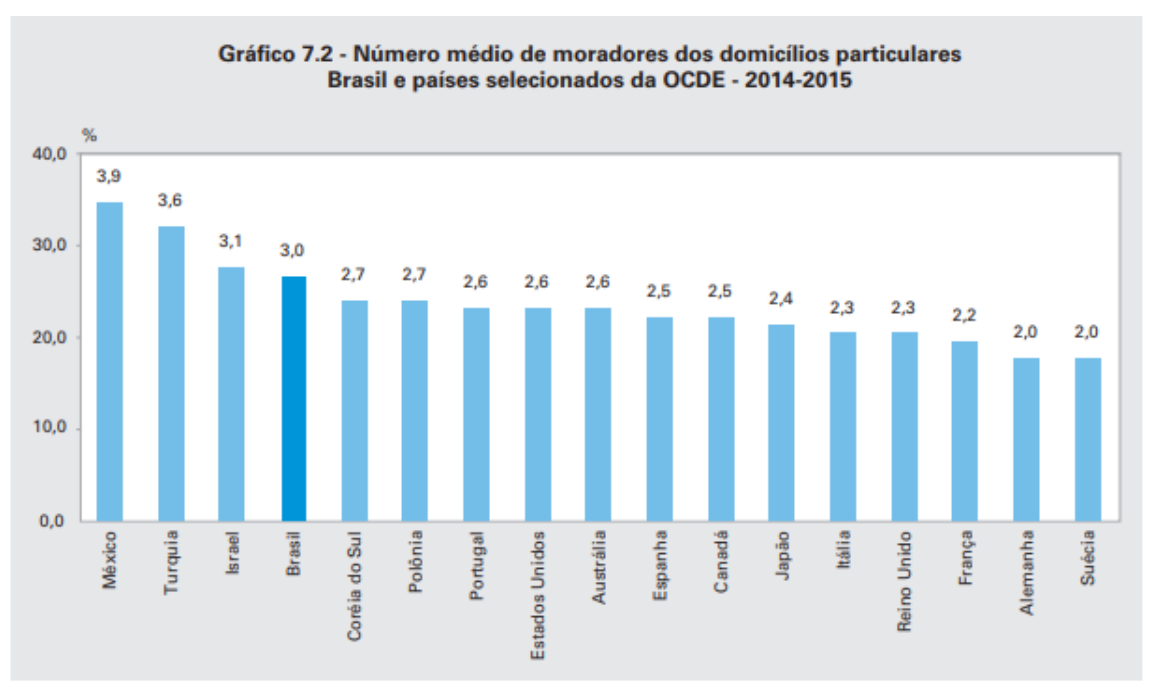

FIGURA 2: Número médio de moradores dos domicílios particulares Brasil e países selecinados da OCDE - 2014-2015

FONTES: 1. IBGE, Pesquisa Nacional por Amostra de Domicílios 2015. 2. Family size and household composition 2014. In: Organisation for Economic Co-operation and Development. OECD Family Database. Paris, 2015.

Em 2005, a proporção dos domicílios brasileiros que possuem banheiro ou sanitário de uso exclusivo dos moradores era de 93,6\%, sendo que no ano de 2015 esse número elevou para 97,7\%, aumento este considerável tendo em vista a importância dessas instalações em relação a saúde da população. A Figura 3 traz um gráfico que apresenta em números as proporções de domicílios particulares que possuem sanitários ou banheiro para o uso do morador, relativos ao ano de 2015, distribuídos em todas as Unidades Federativas. 
Res., Soc. Dev. 2019; 8(4):e2784867

ISSN 2525-3409 | DOI: http://dx.doi.org/10.33448/rsd-v8i4.867

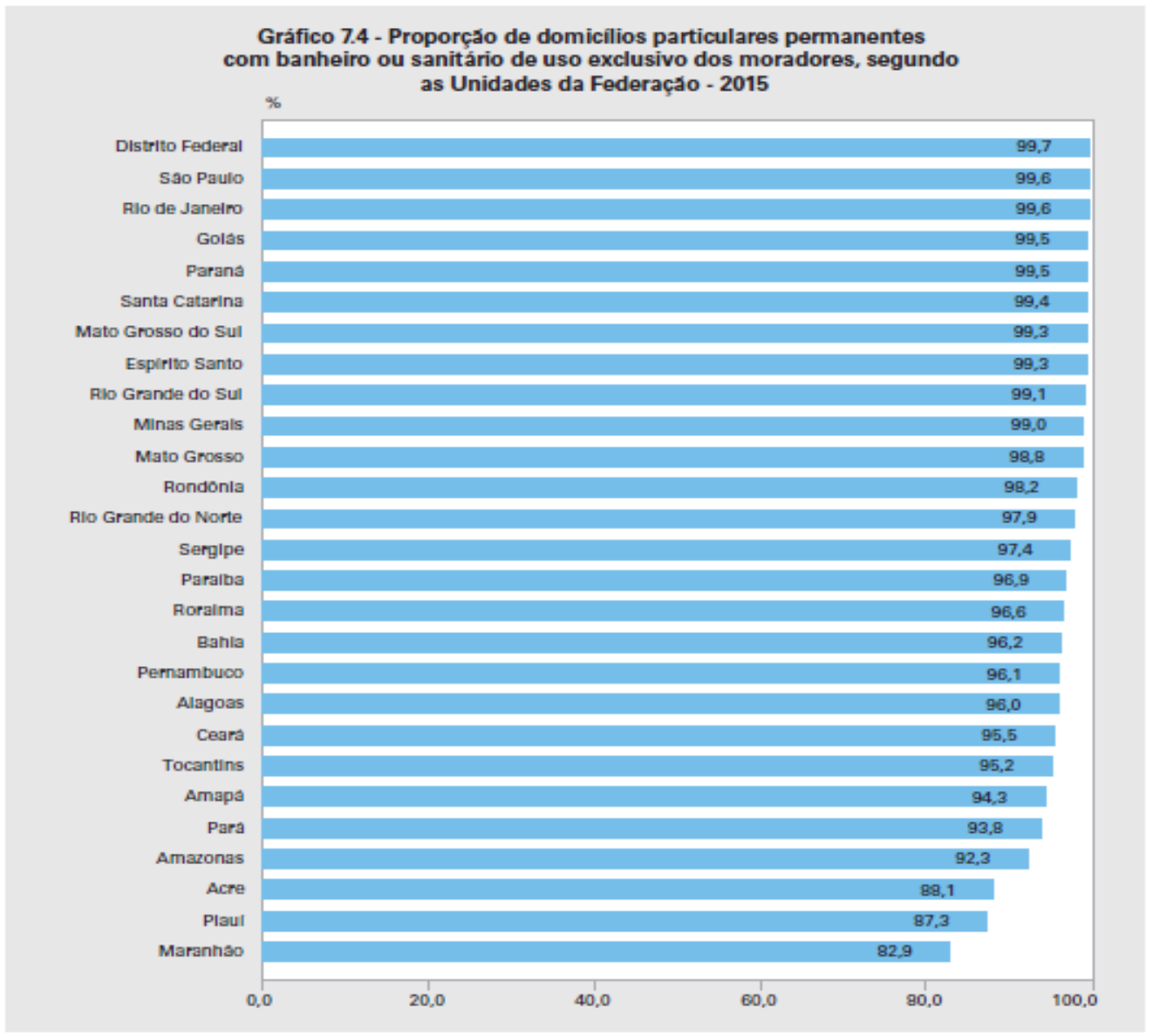

FIGURA 3: Proporção de Domicílios Particulares Permanentes com Banheiro ou Sanitário FONTE: IBGE, Pesquisa Nacional por Amostra de Domicílios (2015)

O Distrito Federal, São Paulo e Rio de janeiro lideram o ranking com maior números de domicílios particulares permanentes que possuem banheiro ou sanitário, com uma porcentagem indicando que quase todos se enquadram. Importante salientar que, mesmo já no ano de 2015, quase a metade dos Estados brasileiros ainda estão abaixo da média dessa proporção, e que estes se encontram na região Norte e Nordeste, com destaques aos Estados de Piauí e Maranhão que estão com valores bem pequenos, tornando-se uma região bastante vulnerável quanto ao risco de doenças de seus moradores relacionadas ao saneamento.

De acordo com a PNAD, ainda existem 1,6 milhão de domicílios particulares permanentes brasileiros sem banheiro ou sanitário no país em 2015, e que no Maranhão esse número chega a 334 mil domicílios, ou seja, um número bastante considerável e que necessita de atenção.

Com relação as proporções de cobertura domiciliar dos serviços públicos de saneamento básico: abastecimento de água por rede geral, esgotamento sanitário por rede 
coletora e coleta direta ou indireta de lixo entre os anos estudado o Brasil teve alguns avanços. Em relação a rede de abastecimento de água essa expansão foi mínima, passando de $82,2 \%$ para $85,4 \%$ no país, já o serviço de esgotamento sanitário por rede coletora passou de $56,6 \%$, em 2005, para 65,3\% em 2015 e o serviço de coleta direta ou indireta de lixo passou de $85,6 \%$ em 2005, para 89,8\% em 2015.

A Figura 4 retrata esses serviços públicos de saneamento básico e traz ainda essa divisão entre a zona urbana e rural para uma melhor visualização de distribuição.

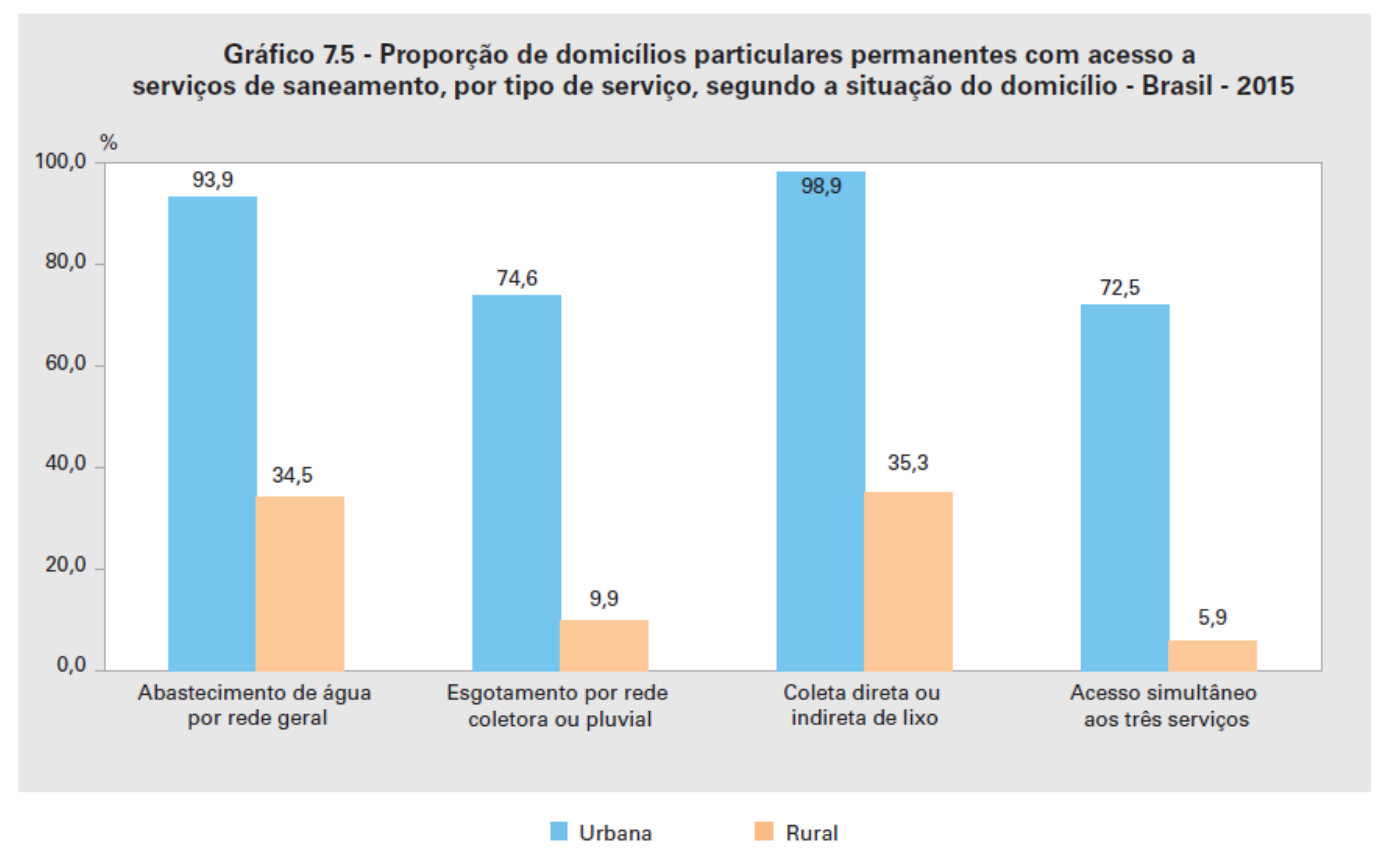

FIGURA 4: Domicílios Particulares Permanentes com acesso a serviços de Saneamento FONTE: IBGE, Pesquisa Nacional por Amostra de Domicílios (2015)

Os serviços de abastecimento de água por rede geral e a coleta de Lixo direta ou indireta tem um valor bastante considerável na Zona Urbana, atingindo quase sua totalidade, enquanto a Zona Rural esse índice é bem menor, não alcança nem a metade em percentual, pontos estes bastante importantes para um desenvolvimento na região, bem como grande influenciador na saúde da população. Em relação ao serviço de Esgotamento por rede coletora ou pluvial o índice na Zona Urbana tem um valor razoável, porem esse serviço é bem restrito aos moradores da Zona Rural a qual não chega nem a 10\% desses domicílios atendidos com esgotamento sanitário, dados estes que devem ser analisados bem pelos gestores públicos, pois até mesmo em locais mais afastados dos centros urbanos é necessário que ao menos se tenham disponíveis a essa parcela da população soluções mais adequadas como, por exemplo, fossas sépticas ou poços artesianos. 
Os indicadores apresentaram forte correlação entre o acesso domiciliar aos serviços de saneamento e a cor ou raça da pessoa de referência do domicílio. A figura 5, apresenta a evolução do acesso simultâneo aos três serviços de saneamento básico, entre os domicílios em que a pessoa de referência é branca, em comparação com aqueles onde a pessoa de referência é preta ou parda.

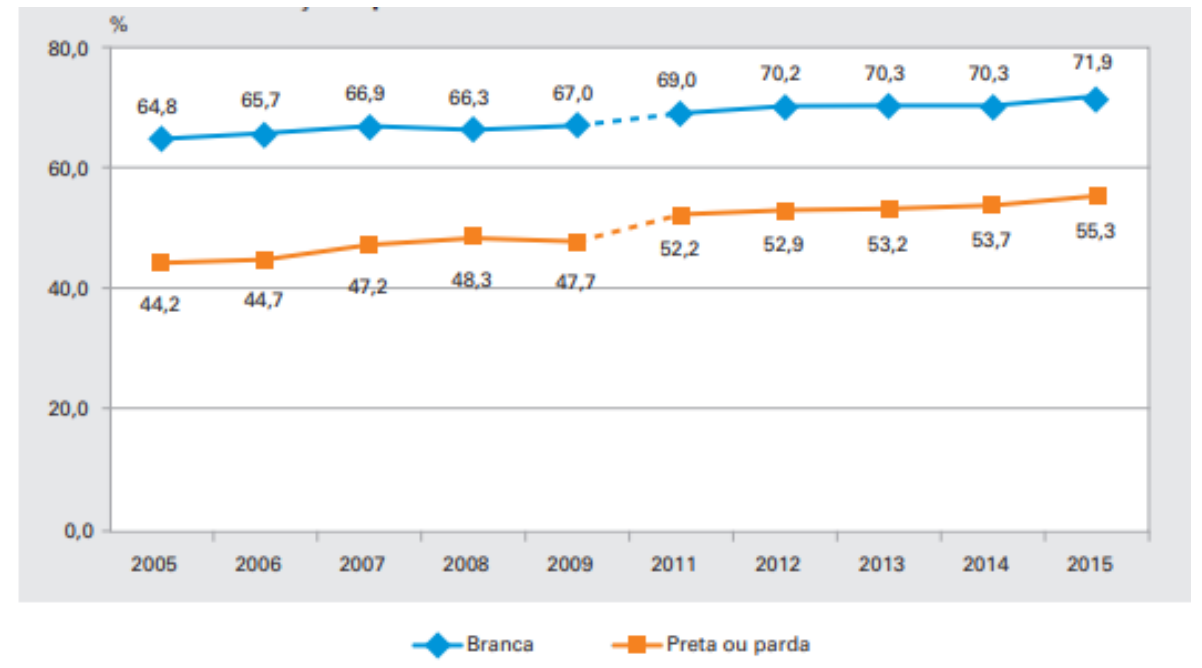

FIGURA 5: Proporção de domicílios particulares permanentes com acesso simultaneo aos três serviços de saneamento básico, segundo a cor ou raça da pessoa de referencia do domicílio - Brasil - 2005/2015

FONTE: IBGE, Pesquisa Nacional por Amostra de Domicílios 2005/2015.

De acordo com os dados, em 2015 os domicílios onde a pessoa de referência é branca apresentam 16,6 pontos percentuais acima em relação à verificada entre os domicílios com pessoas de referência preta ou parda. Em 2005, essa diferença era de 20,6 pontos percentuais. Houve uma redução nessa década, porém ainda são valores bem consideráveis.

Em relação as diferentes regiões, o indicador de acesso simultâneo aos três serviços de saneamento básico também apresenta resultados bastante desiguais, chegando a $86,2 \%$ no Sudeste, $63,1 \%$ no Sul, 50,8\% no Centro-Oeste, 40,8\% no Nordeste e apenas 18,2\% no Norte. Entre as Unidades da Federação os casos mais díspares são do Estado de São Paulo, com 92,4\%, e do Amapá, com 3,3\%.

\section{Conclusão}

O saneamento básico é um direito fundamental da população e está assegurado pela Lei Federal 11.445/07 (Lei Federal do Saneamento Básico), tratando de um conjunto de serviços que devem ser disponibilizados à todos pelos três níveis de governo, onde estes devem adotar medidas que visem a melhoria da vida e da saúde da população, seu bem-estar 
físico mental e social. Diante disso a abordagem deve ser tratada com mais seriedade governamental, principalmente por se tratar de uma política Nacional que trata de serviços de água e saneamento prestado pelo Estado ou empresa concessionária de serviço público, abrangendo o abastecimento de água potável, esgotamento sanitário, limpeza urbana e manejo de resíduos sólidos e drenagem e manejo das águas pluviais urbanas.

O estudo foi realizado a partir dos dados disponibilizados pelo Instituto Brasileiro de Geografia e Estatística (IBGE), no qual se realizou uma breve análise da situação dos serviços de saneamento disponibilizados em cada região do país em relação aos domicílios particulares permanentes, focando principalmente no abastecimento de água, esgotamento e coleta de lixo. Essas informações foram retratadas em figuras para melhor compreensão e divulgação dos dados, demonstrando dados quanto a população atendida, sua representatividade em cada região do país, bem como a distinção entre as áreas urbanas e rurais.

Percebeu-se que dentre os quesitos estudados, o que se refere a esgotamento tem os menores níveis de acesso a população comparado aos demais, o que torna preocupante, sendo necessário um olhar crítico dos gestores públicos em relação a isso. Os serviços disponibilizados no estudo quanto ao saneamento têm valores bastante consideráveis na Zona Urbana, enquanto a Zona Rural esse índice é bem menor, quase a metade em percentual, pontos estes bastante importantes para um desenvolvimento na região, bem como grande influenciador na saúde da população.

$\mathrm{O}$ acesso aos serviços adequados de água e esgoto é um importante determinante das condições de vida da população e da salubridade do meio ambiente, no qual se evidencia que a falta de saneamento está atrelada a diversos problemas na saúde da população. São as boas condições a esse conjunto de fatores relacionados ao saneamento que podem garantir uma qualidade de vida da população. O país que possui um saneamento básico adequado possui um requisito essencial para seu desenvolvimento, pois são estes serviços que geram a melhoria na qualidade de vida das pessoas, da saúde, reduz a mortalidade infantil, traz melhorias na educação, gera aumento em índices do turismo, valorização de seu território, na economia, dentre outros fatores essenciais.

A partir da aferição dos referidos dados se pode concretizar o descumprimento a legislação e a necessidade de se impor medidas coercitivas para o atendimento da população às diretrizes legais, pois é necessário um trabalho em conjunto da sociedade e do poder público na preservação ambiental e assim garantir um meio ambiente sustentável, sendo este um preceito constitucional de aplicação direta da Constituição Federal e por todas deve ser respeitada. 
Evidencia-se assim um caráter Interdisciplinar de atuação legislativa, social e administrativa para trazer eficácia prática das medidas, o que acabará por trazer melhorias em diversos setores sociais.

Diante o contexto trabalhado no presente estudo, sugere-se para pesquisas futuras, estudos de casos que possam analisar e demonstrar situações locais, delimitar alguma região para uma melhor visibilidade dos resultados aqui demonstrados.

\section{Referências}

Barat, J. (1998). O financiamento da infra-estrutura urbana: os impasses, as perspectivas institucionais, as perspectivas financeiras. In: IPEA. Infra-estrutura: perspectivas de reorganização (financiamento). Brasília .

Demoliner, Karine Silva. (2008). Água e saneamento básico: regimes jurídicos e marcos regulatórios no ordenamento brasileiro. Porto Alegre. Livraria do Advogado.

Gil, Antonio Carlos. (2008). Métodos e técnicas de pesquisa social. 6ed. São Paulo.Atlas.

Hespanhol, Ivanildo. (2006). Água e saneamento básico. In: REBOU- ÇAS, Aldo Da Cunha; Braga, Benedito; Tundisi, José Galizia (Orgs.). Águas doces no Brasil: capital ecológico, uso e conservação. 3ed. São Paulo. Escrituras.

IBGE. (2016). Síntese de indicadores sociais : uma análise das condições de vida da população brasileira. Coordenação de População e Indicadores Sociais. (Estudos e pesquisas. Informação demográfica e socioeconômica, ISSN 1516-3296; n. 36). Rio de Janeiro.

IPEA. Instituto de Pesquisa Econômica Aplicada. (2010). Objetivos de Desenvolvimento do Milênio: Relatório Nacional de Acompanhamento. Brasília.

Mejia, A. et al. (2003). Água, redução de pobreza e desenvolvimento sustentável. Série Água Brasil (Banco Mundial). Brasília.

Moreira, T. \& Carneiro, M. C. F. (2005). A parceria público-privada na infra-estrutura econômica. Revista do BNDES, Rio de Janeiro, 1(2):27-46. 
Res., Soc. Dev. 2019; 8(4):e2784867

ISSN 2525-3409 | DOI: http://dx.doi.org/10.33448/rsd-v8i4.867

Oliveira Filho, A. (2006). Institucionalização e desafios da Política Nacional de

Saneamento: um balanço prévio. Saneamento e Municípios. Brasília.

Feijó, Cláudia Cristina Ciappina Pires \& LUIZ, Leliana Casagrande. (2009). Gestão de Recursos Hídricos: Gestão Ambiental. São Paulo: Pearson Education do Brasil.

Saiani, Carlos César Santejo \& Júnior, Rudinei Toneto. (2007). Evolução do Acesso a Serviços de Saneamento Básico no Brasil (1970 a 2004). Campinas - SP.

Sarlet, Ingo Wolfgang \& Fensterseifer, Tiago. (2011). Direito Constitucional Ambiental: estudos sobre a Constituição, os Direitos Fundamentais e a proteção do ambiente. São Paulo: Revista dos Tribunais.

Trindade, Antonio Augusto Cançado. (1993). Direitos humanos e meio ambiente: paralelo dos sistemas de proteção internacional. Porto Alegre.

\section{Porcentagem de contribuição de cada autor no manuscrito}

Fernanda Beatryz Rolim Tavares - 40\%

Fernando Chagas de Figueiredo Sousa - 20\%

Vanessa Érica da Silva Santos - 20\%

Érika Lira da Silva - 20\% 